\title{
Telessaúde em apoio à Atenção Primária à Saúde no Brasil
}

\author{
Telehealth in support of Primary Care in Brazil
}

Eno Dias de Castro Filho*

\begin{abstract}
Resumo
Inúmeros pontos de estrangulamento têm sido enfrentados na estratégia Saúde da Família, e muitos deles dizem respeito à resolutividade. O Projeto Telessaúde pode impactar favoravelmente na resolutividade. Os custos em dependência nacional de aguardar para adotar essas tecnologias somente no futuro devem ser levados em conta. A rede da Saúde da Família se constitui, em larga medida, por recém-formados e pelos especialistas focais de órgãos, sistemas, gênero ou faixa etária que, na representação ultrapassada do SUS como pirâmide, estariam alocados em seu "topo". As condutas dos recém-formados e dos especialistas focais, quando trabalhando em APS, não terão a excelência requerida se não lhes for oferecida a qualificação específica para este cenário. A disponibilização de segunda opinião via internet por especialistas em Atenção Primária pode ser a alternativa de suporte durante o longo período necessário para uma reciclagem tão ampla em escala nacional. Ao lado da teleassistência aqui sugerida, teleducação também deve integrar o Telessaúde. No entanto, conteúdo não solicitado e pedagogia de concepção "bancária", altamente presentes na internet, são pouco úteis. As escolhas neste campo devem observar as conclusões de revisões sistemáticas sobre o que é efetivo e o que não é, em desenvolvimento profissional contínuo.
\end{abstract}

\begin{abstract}
The Family Health Strategy has faced numberless bottlenecks, many of them with respect to the capacity to solve problems. The Telehealth Project can improve this capacity. The cost in terms of national dependence resulting from the delay in adopting these technologies must be taken into account. The Family Health Program counts mainly with recently graduated physicians or with medical specialists, who in the former organization of the Unified Health System would have built the top of the pyramid. However the performance in Primary Care of both recently graduated practitioners and medical specialists will not reach the required excellence without specific qualification for this field. The availability of a second opinion from specialists in Primary Care through the Internet could represent an alternative during the long period of time necessary for such a wide-ranging recycling on national level. Besides the telemedicine suggested here, telelearning also must integrate the Telehealth Project. Unrequested content and education following the "banking" concept however, widely present in the Internet, are of little use.
\end{abstract}

Palavras-chave: Conhecimento; Atenção

Primária à Saúde; Informática Médica; Saúde da

Família; Educação Baseada em Competências.
Key Words: Knowledge; Primary Health Care; Medical Informatics; Health Family; Competency-Based Education.

*Médico de Família e Comunidade, Mestrado em Educação, Diretor Científico SBMFC 2004-2008, Coordenador do Núcleo Telessaúde/RS. 
The choices in this field must follow the conclusions of systematic reviews about what is and what is not effective in continued professional development.

\section{Introdução}

O desenvolvimento do Sistema Único de Saúde (SUS) alcançou um novo patamar a partir da consolidação da estratégia Saúde da Família (SF) como política de Estado. Sendo estabilizada entre as estratégias da nação, ampliou decisivamente o acesso dos cidadãos a cuidados integrais e continuados à sua saúde. Entretanto, inúmeros pontos de estrangulamento têm sido enfrentados, e muitos deles dizem respeito à resolutividade da rede de cuidados.

Como parte de um conjunto expressivo de ferramentas utilizadas na qualificação dos profissionais de saúde, a telemática pode impactar favoravelmente na resolutividade do SUS. A queda nos custos de hardware e telecomunicações e o desenvolvimento de software na área abrem espaço para novas soluções adaptadas aos gargalos dos serviços. A Organização Mundial da Saúde, a UNESCO e a International Telecommunication Union (ITU) têm-se dedicado a estudar este potencial, e suas diretrizes integram as bases do Projeto Telessaúde, do Ministério da Saúde (MS) brasileiro. Especialmente, devese destacar, como referência, o documento Guidelines for a country feasibility study on telemedicine, de 2003, produzido pelo Centro Norueguês para Telemedicina (NST), por encomenda da OMS. Nele se condensaram resultados de estudos de praticabilidade da telemedicina em diferentes países como África do Sul, Cuba e outros.

Telessaúde abrange teleducação, suporte à pesquisa em saúde, suporte para a gestão e telemedicina. Telemedicina é definida como ações de saúde em que as tecnologias da informação e comunicação permitem provimento de suporte ou cuidados independentemente de onde se situa o usuário do serviço, o profissional de saúde e a própria informação.

A experiência já desenvolvida e estudada chama atenção para a necessidade de um planejamento que leve em conta também os erros já efetivados internacionalmente ou identificados como possíveis.

Nesse sentido, é necessário prudência diante das pressões e expectativas geradas pelos grupos econômicos ligados à área e, especialmente, ao risco de substituir investimentos e recursos de custeio que seriam necessários em outras operações ainda mais fundamentais para a resolutividade dos cuidados de saúde. $\mathrm{Na}$ verdade, tanto os custos de manutenção de longo prazo, como os de substituição de equipamentos danificados, furtados ou ultrapassados, os de treinamento de pessoal e pagamento de instituições colaboradoras e fornecedoras devem estar previstos para dimensionar o esforço nacional em equilíbrio com os relevantes objetivos buscados. De outro lado, os custos em dependência nacional da alternativa de aguardar para adotar essas tecnologias somente no futuro também devem ser levados em conta.

Além disso, é fundamental, desde o início, constituir espaços-ponte entre as comunidades de profissionais de saúde, a comunidade acadêmica, a comunidade de telecomunicações e informática, os órgãos governamentais e os usuários do sistema de saúde. Um pequeno comitê orientador da iniciativa deve trabalhar em conjunto com uma rede maior de participantes, a fim de que uma operação de grande envergadura não seja subaproveitada e não incorra em equívocos que um amplo e permanente diálogo pode evitar.

\section{Contexto}

É imprescindível definir com nitidez tanto a necessidade que se quer atender como o cenário em que ela se apresenta para delinear o melhor aproveitamento dos recursos da telessaúde em nosso país.

As pesquisas avaliativas já realizadas sobre a estratégia Saúde da Família apontam para uma grande extensão do acesso ao Sistema (embora ainda haja grandes vazios, especialmente na região Norte, com suas conseqüências inclusive no plano da ocupação nacional do território e sua segurança), acompanhado por um insuficiente desenvolvimento do suporte à Atenção Primária. Insuficiente tanto em termos de recursos diagnósticos, como de referência e 
contra-referência, como no desenvolvimento profissional contínuo dos trabalhadores (aqui incluídos os problemas da precarização das relações de trabalho e os da manutenção ou aquisição das competências específicas para o trabalho em Atenção Primária à Saúde). A telemática não incide necessariamente sobre a precarização das relações de trabalho, mas pode impactar positivamente na solução dos demais.

O descompasso entre expansão da rede e adequação dos profissionais torna necessário aguçar o olhar. A representação tradicional dos sistemas de saúde empregava o desenho de uma pirâmide. Em sua base, estariam profissionais com uma formação simplificada e, em seu topo, os especialista focais de órgãos determinados do corpo humano, sistemas específicos, gênero ou faixa etária - ou, ainda, especialistas focados em cenários nos quais a prestação de serviços de saúde demanda sempre equipamentos de alto custo, como CTIs. Ora, esta representação não se aplica às nações em que se organizaram sistemas de saúde altamente resolutivos e custo-efetivos. Porque demonstraram que o profissional necessário na chamada rede básica não é um profissional básico ou pouco qualificado, mas também especializado. Seu cenário de trabalho os expõe o tempo todo a problemas de saúde altamente complexos. A indiferenciação clínica dos problemas é maior, sua apresentação é mais freqüentemente inicial e, por sua interação intensiva com fatores familiares, comunitários e sociais também altamente complexos, requerem especialistas no cuidado integral. E no Brasil a imagem da pirâmide se aplica ainda menos, pois aqui a rede da Saúde da Família se constitui em larga medida pelos mesmos especialistas focais que a pirâmide esperaria encontrar em seu pretenso topo. Anestesistas, cirurgiões plásticos, nefropediatras, obstetras são defrontados diariamente com crianças que sofreram abuso sexual, com homens sedentários que têm artrose, com diabéticos em cuja casa quem cozinha é uma comedora compulsiva... As condutas dos especialistas focais, quando trabalhando em APS, não terão a excelência requerida se não lhes for oferecida a qualificação específica necessária para este cenário. A disponibilização de segunda opi- nião de especialistas em Atenção Primária pode ser a alternativa de suporte durante o longo período necessário para uma reciclagem tão ampla em escala nacional.

Ou seja, as necessidades de educação à distância, de consultoria/segunda opinião são muito diferentes do que se conceberia se a velha pirâmide fosse a referência de interpretação da realidade. Nosso SUS é muito mais como uma teia ainda em construção do que qualquer figura geométrica pronta poderia sugerir.

É diante desse contexto particular que se busca a contribuição que a telemática pode aportar à Atenção Primária no Brasil. É nele que se põe a tarefa de aproximar a resolutividade desse nível do Sistema dos 85\% internacionalmente testados e propugnados.

\section{Flexibilidade}

Entende-se a telemática como ferramenta e canal maleável, com ênfase de utilização mutável à medida que se desdobram outras iniciativas tendentes a resolver os atuais gargalos do Sistema de Saúde. No último decênio, o MS tem investido na multiplicação de alternativas de capacitação para a Saúde da Família. Mais recentemente, compreendendo a particularidade desta carência no campo da Medicina, desenvolve-se uma política de expansão das Residências em Medicina de Família e Comunidade (MFC) credenciadas pela CNRM. São procuradas, também, as formas de realizar uma capacitação em larga escala à distância em curto período. Quando essas iniciativas (dentre outras, como investimentos em equipar as Unidades de Saúde da Família com diferentes recursos), mostrarem seu impacto de modo mais significativo, é provável que a demanda para segunda opinião em MFC ou em especialidades focais diversas diminua. Por outro lado, pode haver aumento da demanda de apoio telediagnóstico, como interpretação de exames de fundo de olho, ECG, colposcopia etc.

Esta variação já pode ser identificada quando enxergamos as imensas diferenças regionais das necessidades de saúde no Brasil. Exemplo disso são as proporções entre população e equipes de Saúde da Família. De 2.500 a 4.500 (portaria recente reduziu o teto para quatro mil, ainda muito 
alto) habitantes por equipe, tal variação determina o quanto de tempo cada profissional pode dedicar a cada pessoa sob seu cuidado, aqui incluídas as teleconsultorias entre pontos da teia. A extensão de área e os acidentes geográficos do espaço sob responsabilidade de uma mesma equipe, igualmente, determinam o quanto de seu tempo poderá ser dedicado ao trabalho dentro da unidade e o quanto será despendido apenas com deslocamento dos profissionais no território.

De outro lado, há localidades nas quais a presença de MFCs já é substantiva. Porém, há regiões em que o difícil acesso a meios diagnósticos e de serviços de referência é imensa. Há também as grandes diferenças entre locais nos quais há e onde não há experiências prévias de telemedicina ou telemática na saúde em geral. E ainda é necessário levar em conta as discrepâncias de disponibilidade de infra-estrutura de internet com banda larga. Isso interfere, tanto quanto o processo de trabalho preexistente, em escolhas entre alternativas como supervisão clínica on-line ou off-line. As necessidades de cada situação deverão, pois, ser enfocadas particularmente para estipular o padrão mais custo-efetivo de telessaúde em APS. A estratégia de implantação deve buscar a máxima eqüidade com vistas ao emparelhamento na superação dos diferentes déficit. Do mesmo modo, o imprescindível sistema de avaliação a erigir deve ter a capacidade de cotejar os benefícios em relação às necessidades inicialmente identificadas, assim como os custos em relação a alternativas disponíveis para satisfazê-las.

\section{Padronização}

Ao lado da flexibilidade, alguns elementos de padronização também deverão estar presentes. Alguns deles derivam da política nacional de telecomunicações e de informatização. Sistemas Operacionais, hardware e desenvolvimento da infra-estrutura de internet serão eleitos em sintonia com essa política. Padrões éticos e de confidencialidade devem obedecer às emanações do Conselho Federal de Medicina e outros órgãos pertinentes. Os princípios gerais são os da Atenção Primária à Saúde, e o enfoque clínico também.

\section{Eixos}

a) Teleducação

A educação à distância para a Atenção primária à Saúde é uma ferramenta importante que pode ser tornada disponível por meio da telemática. Entretanto, as escolhas neste campo devem observar as conclusões das revisões sistemáticas sobre o que é efetivo e o que não é, em desenvolvimento profissional contínuo. A Biblioteca Cochrane disponibiliza material de alta qualidade a este respeito, e há muito material sobre isto em vários periódicos médicos de grande penetração. Em síntese, conteúdo não solicitado e pedagogia de concepção "bancária" (na acepção de Paulo Freire) são altamente presentes na internet e, nessa mesma proporção, são pouco úteis. Recomendamos a estratégia de disponibilizar gratuitamente a melhor literatura científica disponível e ofertar aos profissionais a oportunidade de escolher o mix que melhor lhes convêm. A conquista da própria Biblioteca Cochrane em sua íntegra para acesso gratuito por meio da BVS é o melhor exemplo dessa literatura. Recomendamos que o banco de revisões conhecido como Clinical Evidence seja disponibilizado do mesmo modo, e seguramente se indica também o acesso ao InfoPoems. Ambos também estão portados para palmtops, o que incrementa grandemente seu potencial de utilidade em apoio à APS. A abertura de um diálogo com o MEC, tendo em vista um padrão mais aberto de acesso ao Portal da CAPES, teria igualmente uma relevância da maior grandeza. Conferências virtuais unidirecionais seriam mais exceção do que regra, e teriam de estar dimensionadas de acordo com a identificação de necessidades ou a premência de comunicação de novas diretrizes de grande impacto clínico, dadas as evidências da inutilidade de educação em saúde não solicitada. Em todos os casos, a adequação de todas essas iniciativas aos padrões de atualização de títulos de especialista médico deverá ser objeto de exame.

A construção de padrões e bancos de intercâmbio para as pesquisas de pequeno porte que constantemente são expostas em mostras e congressos, e até aqui não 
organizadas para a disponibilidade on-line, também seria iniciativa relevante e relativamente simples em termos operacionais.

\section{b) Teleassistência}

Como visto no subtítulo Contexto, nossa teleassistência deve ter em foco nossa pirâmide invertida. A rede de suporte precisa proteger os pacientes de condutas inapropriadas padronizadas para outros níveis do sistema, precisa proteger os profissionais de seu próprio viés de especialista focal, precisa proteger os recém-formados do isolamento e proteger o orçamento público do desperdício.

Essa dimensão de "ajustamento" aponta para a necessidade de uma "regulação" em Telessaúde para APS. Do mesmo modo que ocorre quanto aos serviços de urgência e emergência, onde o SAMU conta com o papel de regulador. O objetivo é aproximar problema concreto e solução adequada. Retomando os exemplos anteriores, pouco adiantaria agendar um nefropediatra, para dar teleconsultoria a um cirurgião plástico atendendo na SF, para discutir o caso de uma menina com disúria sem atentar para o fato de ela sofrer abuso sexual dentro de casa e estar também com DSTs. O nefropediatra está treinado para receber crianças com infecção urinária atual ou passada, investigar dano de parênquima renal, instituir tratamento e profilaxia etc. Supõe-se que, para chegar a ele, a criança foi antes atendida por outro médico habilitado a distinguir entre essa e outras condições, que solicitou a referência por necessitar de recursos indisponíveis em seu meio. O nefropediatra não abre o leque de possibilidades, ele pressupõe uma triagem prévia. Ele não é o médico mais indicado para orientar sobre uretrite por clamídia oriunda de estupro, nem para investigar a possibilidade de outras DSTs ou lesões coexistentes, tampouco para orientar a intervenção sobre este drama familiar grave. Esta criança mereceria ter sido protegida de uma perda de tempo com discussão de seu caso por teleconsultoria com o profissional inapropriado (por mais qualificado que fosse em sua área), e das condutas que daí adviriam, além da ausência das condutas de que ela realmente necessitaria.
Quem pode efetivar essa aproximação entre necessidade e solução apropriada é o médico regulador. Ele deve receber 100\% das solicitações de segunda opinião para exercer sua função. Evidentemente, para ser qualificado para a tarefa, ele deve ser um especialista em cuidado integral, a despeito de idade, gênero, órgãos ou sistemas em sofrimento. O especialista em Medicina de Família e Comunidade é este profissional. Por certo, além de regular as situações que realmente façam necessário teleacesso a um especialista focal, o MFC irá disponibilizar a solução para a maioria das dúvidas geradas no contexto de APS. Consolidando respostas apropriadas e fundamentadas nas evidências adequadas, a cada teleconsultoria de um MFC se acrescentaria conhecimento disponível nacionalmente nos moldes de uma PFP (perguntas frequentemente perguntadas, ou FAQ, em inglês), poupando a necessidade de repetições.

Para viabilizar que os núcleos estaduais de Telessaúde APS possam recrutar esses especialistas da integralidade, a identificação dos serviços e programas de residência com maior tradição na área é um caminho. Também a Sociedade Brasileira de Medicina de Família e Comunidade (SBMFC) pode ser consultada para informar sobre suas listas estaduais de MFCs titulados por concurso reconhecido pela Associação Médica Brasileira (AMB).

No mesmo sentido, as Diretrizes Clínicas ou guidelines adotadas em apoio à decisão clínica deverão ser elaboradas, revisadas ou validadas com especialistas em MFC. O APS-IVC deve ser utilizado para avaliação sistemática dos conteúdos de suporte à distância para SF. Em relação aos centros de especialistas focais a serem eleitos para a tarefa de segunda opinião, quando necessários, sua designação deverá ser acompanhada de capacitação presencial sobre os princípios da APS.

$\mathrm{Na}$ área de telediagnóstico em imagem e métodos gráficos, é necessário consultar o DAB e os gestores estaduais e municipais para definir o que já é disponível em termos de recursos para a rede de SF.

Porto Alegre, 12 de dezembro de 2005 (atualizado na Páscoa de 2008). 
Obs.: Documento apresentado pela SBMFC ao MS e colaboradores em 2005, início da discussão nacional do Projeto Telessaúde para APS. Discretamente atualizado em março de 2008.

\section{Endereço para Correspondência:}

Rua 28 de setembro, sala 605,

Rio de Janeiro RJ

CEP: 20.551-031

\section{Endereço Eletrônico:}

enofilho@uol.com.br 